\title{
The Analysis of Logistics Influence of the Important Node Cities of Beijing-Tianjin-Hebei
}

\author{
Li Xiaojun, Han Song, Xie Weikun \\ Institute of Information, Beijing Wuzi University, Beijing, China
}

Email address:

543834058@qq.com (Li Xiaojun), songhan82@163.com (Han Song),18210175078@163.com (Xie Weikun)

To cite this article:

Li Xiaojun, Han Song, Xie Weikun. The Analysis of Logistics Influence of the Important Node Cities of Beijing-Tianjin-Hebei. International Journal of Business and Economics Research. Vol. 6, No. 5, 2017, pp. 88-92. doi: 10.11648/j.ijber.20170605.11

Received: July 30, 2017; Accepted: August 18, 2017; Published: September 1, 2017

\begin{abstract}
The paper chooses the index of urban logistics competitiveness, constructs the evaluation system of urban logistics competitiveness, uses SPSS17.0 to select the four most competitive cities in the 13 major cities of Beijing-Tianjin-Hebei: Beijing, Tianjin, Shijiazhuang, Tangshan, and the four cities are used as the important node cities for the logistics development of Beijing-Tianjin-Hebei. Based on the breaking point theory, using breaking point formula, field strength formula and radiation radius formula, the paper can calculate the location and field strength between the four key nodes cities and the rest of the city, then the paper select the boundary field strength to calculate the logistics impacts of the four cities which are the most competitive in Beijing-Tianjin-Hebei. Finally paper can determine the scope of their impacts. According to the above steps paper can analyze the Beijing-Tianjin-Hebei regional logistics development status, and put forward the relevant countermeasures and suggestions about logistics integration of Beijing-Tianjin-Hebei.
\end{abstract}

Keywords: Regional Logistics Integration, Logistics Influence, Breaking Point Theory

\section{Introduction}

Flourishing quickly in the past 10 years in China, the logistics economy has promoted the construction of logistics cluster. According to the "The fourth national logistics park (base) investigation report", various logistics parks has reached 1210 that some are in operation, or under construction, or in planning [1] [2]. The logistics park brings the aggregation effect, but at the same time the problem of high vacancy rate and low efficiency has increasingly become prominent [3]. Many scholars found that the influence of urban logistics can provide a good idea for people to plan the rational urban logistics park.

The theory of break points proposed by Kuvers in 1949, is often used to analyze the influence of the city. The break point model can be applied to determine the radiation range of urban logistics [4]. The scope of the city's logistics impact is the maximum geographical extent of the city's impact on its surrounding areas in terms of logistics.

According to the statistical data in the database China, paper using Beijing-Tianjin-Hebei as the object establishes the evaluation index system of comprehensive competitiveness of urban logistics. This paper constructing the model of regional logistics breaking point and analyzing the logistics radiation range of important cities in Beijing-Tianjin-Hebei, which is based on the theory of broken point. The overall analysis of the important nodes of the city's logistics influence, which can be the development of Beijing-Tianjin-Hebei logistics for better planning.

\section{Method}

\subsection{Establishment of Evaluation Index of Comprehensive Competitiveness of Urban Logistics}

Through considering economic and logistics development status of the Beijing-Tianjin-Hebei region and reading the relevant literature [12] [13], the establishment of Beijing-Tianjin-Hebei regional logistics comprehensive competitiveness evaluation index system is as follows. And the index data could be found in Chinese Statistical Database. 
Table 1. The index system.

\begin{tabular}{ll}
\hline First-level indexes & Second-level indexes \\
\hline & Urban GDP \\
Overall level of regional economic development & The total population of the city \\
& The total retail sales of social consumer goods \\
& The number of above-scale industrial enterprises \\
Regional logistics industry demand situation & Above-scale industrial output value \\
& The total freight \\
& Railway freight \\
Regional logistics circulation capacity & Road freight \\
& Urban road area \\
& Number of persons engaged in transportation, warehousing and postal services \\
Current Situation of Regional Logistics Environment & Number of mobile phone users at the end of the year \\
& Number of Internet Broadband Access Users \\
\hline
\end{tabular}

\subsection{The Selection of Important Node City}

Through factor analysis, the paper extracts the important factors to evaluate the logistics competitiveness of the cities of Beijing-Tianjin-Hebei, and sort the factor scores for each city, then select the logistics competitiveness of the top four cities as an important node city.

The process and results of factor analysis are as follows.

\subsubsection{The Total Variance of the Interpretation}

It can be seen from Table 1 that the initial eigenvalues of the three principal components are more than 1 and the cumulative contribution rate is $96.426 \%$, which indicate that the three eigenvectors corresponding to the eigenvalue contains $96 \%$ of the information, so the three eigenvectors corresponding to the three eigenvalue can be used as a new comprehensive indicators that can evaluate logistics competitiveness of 13 cities in Beijing-Tianjin-Hebei region.

Table 2. Total Variance Explained.

\begin{tabular}{|c|c|c|c|c|c|c|}
\hline \multicolumn{7}{|c|}{ Total Variance Explained } \\
\hline & \multicolumn{3}{|c|}{ Initial Eigenvalues } & \multicolumn{3}{|c|}{ Extraction Sums of Squared Loadings } \\
\hline & Total & $\%$ of Variance & Cumulative\% & Total & $\%$ of Variance & Cumulative\% \\
\hline 1 & 7.991 & 66.59 & 66.588 & 7.991 & 66.59 & 66.588 \\
\hline 2 & 2.311 & 19.26 & 85.85 & 2.311 & 19.26 & 85.85 \\
\hline 3 & 1.269 & 10.58 & 96.426 & 1.269 & 10.58 & 96.426 \\
\hline 4 & 0.213 & 1.773 & 98.199 & & & \\
\hline 5 & 0.121 & 1.011 & 99.21 & & & \\
\hline 6 & 0.074 & 0.617 & 99.827 & & & \\
\hline 7 & 0.014 & 0.118 & 99.945 & & & \\
\hline 8 & 0.004 & 0.037 & 99.982 & & & \\
\hline 9 & 0.002 & 0.014 & 99.996 & & & \\
\hline 10 & 0 & 0.003 & 99.999 & & & \\
\hline 11 & 0 & 0.001 & 100 & & & \\
\hline 12 & $2.41 \mathrm{E}-06$ & $2.01 \mathrm{E}-05$ & 100 & & & \\
\hline \multicolumn{7}{|c|}{ Extraction Method: Principal Component Analysis. } \\
\hline
\end{tabular}

\subsubsection{The Calculation and Ranking of Logistic Comprehensive Competitive Scores}

As shown in Table 3, the results of comprehensive scores of urban logistics competitiveness in Beijing-Tianjin-Hebei are ranked as follows, the top four in competitiveness: Beijing, Tianjin, Shijiazhuang and Tangshan, so the paper regards these four cities as the important node cities.

Table 3. The rank of comprehensive score of urban logistics competitiveness.

\begin{tabular}{llllll}
\hline City & Factor 1 & Factor 2 & Factor 3 & Composite score & rank \\
\hline Beijing & 3.18 & -0.23 & -0.70 & 2.00 & 1 \\
Tianjin & 0.52 & -0.08 & 3.17 & 0.67 & 2 \\
Shijiazhuang & 0.05 & 1.12 & -0.31 & 0.21 & 3 \\
Chengde & -0.46 & -0.88 & -0.44 & -0.52 & 12 \\
Zhangjiakou & -0.58 & -1.14 & 0.46 & -0.56 & 13 \\
Qinhuangdao & -0.40 & -1.08 & -0.30 & -0.51 & 4 \\
Tangshan & -0.39 & 2.04 & -0.06 & 0.13 & 9 \\
Langfang & -0.35 & -0.43 & -0.60 & -0.38 & 5 \\
Baoding & -0.04 & 0.36 & -0.46 & 0.00 & 7 \\
Cangzhou & -0.39 & 0.79 & -0.33 & -0.14 & 11 \\
Hengshui & -0.41 & -1.07 & -0.27 & -0.51 & 8 \\
Xingtai & -0.34 & -0.42 & -0.29 & -0.34 & 6 \\
Handan & -0.40 & 1.00 & 0.13 & -0.06 & \\
\hline
\end{tabular}




\subsection{The Analysis of Logistics Influence of Important Nodes Cities}

\subsubsection{The Introduction of Break Point Model}

The theory of break point is a theory that studies the interaction between towns and regions, and is often used to determine the influence of the city on the surrounding space.

The larger the city, the more attractive it is; the further the distance between the two cities, the weaker the attraction between them. Because of the city scale and the distance between the cities, the interaction between the two cities will approach the balance. When the interaction reaches equilibrium, there will be a balance, the theory call it "break point" [4].

By calculating the break point, the radiation radius of each city can be further calculated. The breaking point formula, field strength formula and radiation radius formula are as follows:

The breaking point formula:

$$
\mathrm{D}_{\mathrm{i}}=D_{i j} /\left(1+\sqrt{M_{j} / M_{i}}\right)
$$

$D_{i}$ is the distance from $\mathrm{i}$ city to the breaking point; $D_{i j}$ is the distance between the two cities of $\mathrm{i}$ and $\mathrm{j} . M_{i}, M_{j}$ is the size of city $\mathrm{i}$ and $M_{j}$ is the size of city $\mathrm{j}$; $\mathrm{i}$ mean the center city, $\mathrm{j}$ means the surrounding city.

The field strength formula:

$$
F_{i k}=M_{i} / D^{2}{ }_{i k}
$$

$F_{i k}$ represents the radial force of the city of $\mathrm{j}$ in $\mathrm{k} . D_{i k}$ is the distance from $\mathrm{i}$ city to $\mathrm{k}$, and $M_{i}$ is the scale of city $\mathrm{i}$, the paper defines the scale of city as city's GDP. $\mathrm{k}$ is the breaking point.
The radiation radius formula

$$
D_{r}=\sum_{i=1}^{n-1} D_{i k}\left(F_{i k} / \sum_{i=1}^{n-1} F_{i k}\right)
$$

$D_{r}$ is the radius of radiation of city $i$.

\subsubsection{The Calculation of Fracture Points and Field Strength}

In this part, the paper take Beijing as an example.

Getting the data of distance between cities from search. huochepiao. com, then applying breaking point theory, paper can obtain the breaking point and its field strength between Beijing and the surrounding cities of Beijing-Tianjin-Hebei region. As shown in table 4.

In the Beijing-Tianjin-Hebei region, Beijing has the highest logistics competitiveness and its logistics influence is great. From the table, the proportion of the distance between starting city and the break point to the distance between the two cities is basically 0.5 or more, indicating that the logistics scale of Beijing is far larger than other cities. The field strength of break point between Beijing and Langfang is 1.07, which is maximum value; The field strength of break point between Beijing and Hengshui is 0.03, which is minimum value, the reason why Beijing has little power in the logistics of hengshui city is that the distance of Beijing and Hengshui is too far, and the population, transportation, infrastructure and other aspects of Hengshui City, are relatively poor.

The breaking point formula and field strength formula can also be used to calculate the fracture points and field strength of Tianjin, Shijiazhuang, Tangshan and surrounding cities respectively.

Table 4. The breaking point and field strength.

\begin{tabular}{lllllll}
\hline City & $\boldsymbol{D}_{\boldsymbol{i j}}$ & $\boldsymbol{M}_{\boldsymbol{i}}$ & $\boldsymbol{M}_{\boldsymbol{j}}$ & $\boldsymbol{D}_{\boldsymbol{i} \boldsymbol{k}}$ & $\boldsymbol{D}_{\boldsymbol{i k}} / \boldsymbol{D}_{\boldsymbol{i} \boldsymbol{j}}$ & $\boldsymbol{F}_{\boldsymbol{i k}}$ \\
\hline Tianjin & 137 & 2069 & 1413 & 75.01 & 0.55 & 0.37 \\
Shijiazhuang & 283 & 2069 & 1005.3 & 166.76 & 0.59 & 0.07 \\
Chengde & 256 & 2069 & 376.9 & 179.42 & 0.7 & 0.06 \\
Zhangjiakou & 206 & 2069 & 468.4 & 139.58 & 0.68 & 0.11 \\
Qinhuangdao & 293 & 2069 & 291.2 & 213.07 & 0.73 & 0.05 \\
Tangshan & 200 & 2069 & 741.8 & 125.1 & 0.63 & 0.13 \\
Langfang & 64 & 2069 & 433.2 & 43.91 & 0.69 & 1.07 \\
Baoding & 152 & 2069 & 1172.1 & 86.73 & 0.57 & 0.28 \\
Cangzhou & 264 & 2069 & 744.4 & 165.02 & 0.63 & 0.08 \\
Hengshui & 439 & 2069 & 442.4 & 300.19 & 0.68 & 0.02 \\
Xingtai & 387 & 2069 & 747.7 & 241.7 & 0.62 & 0.04 \\
Handan & 439 & 2069 & 993.1 & 259.33 & 0.59 & 0.03 \\
\hline
\end{tabular}

\section{Result}

From the previous calculation and analysis, the paper get the breaking point between an important node in the city and the rest of the city. As shown from the map, the four node city (Beijing, Tianjin, Shijiazhuang, Tangshan) logistics influence on around the city can be observed.

The paper figure out the radiation radius of Beijing is about $70 \mathrm{~km}$ by using the formula of radiation radius. Similarly the radiation radius of Tianjin is about $55 \mathrm{~km}$, the radiation radius of Shijiazhuang is about $64 \mathrm{~km}$, and the radiation radius of Tangshan is about 69. As the figure 2 shows. Beijing has a large area logistics radiation, and the strong logistics radiation area, which is composed of Beijing, Tianjin, Shijiazhuang and Tianjin, is still to be expanded. 


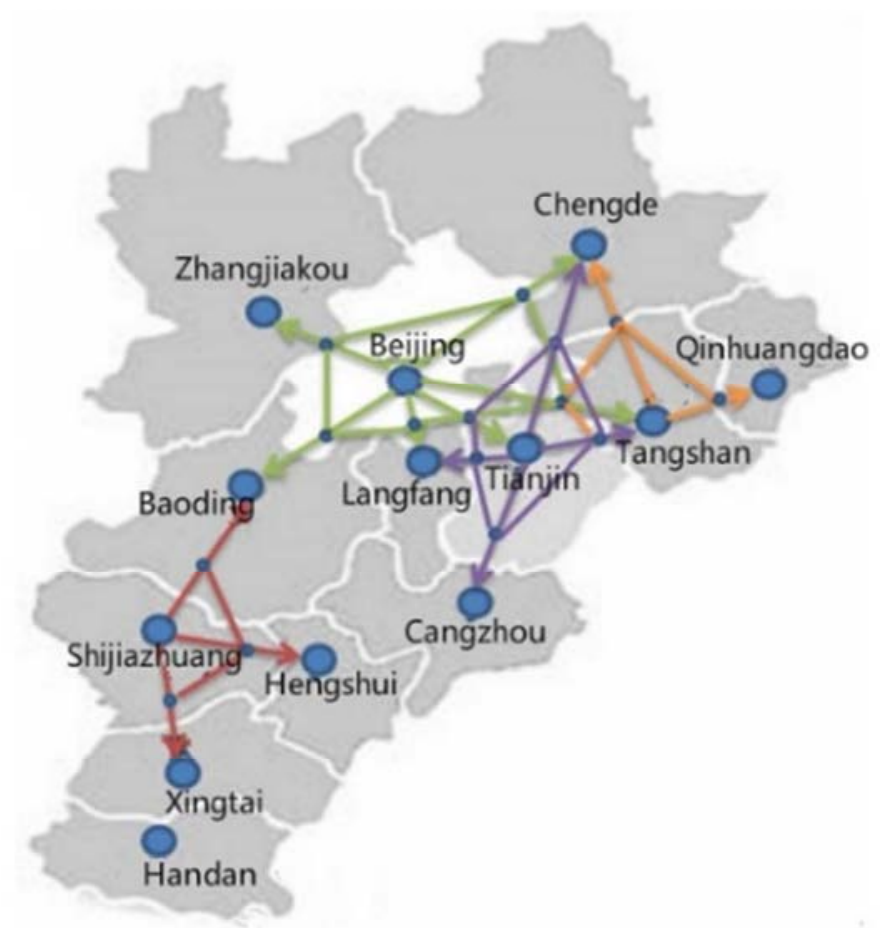

Figure 1. Break point.

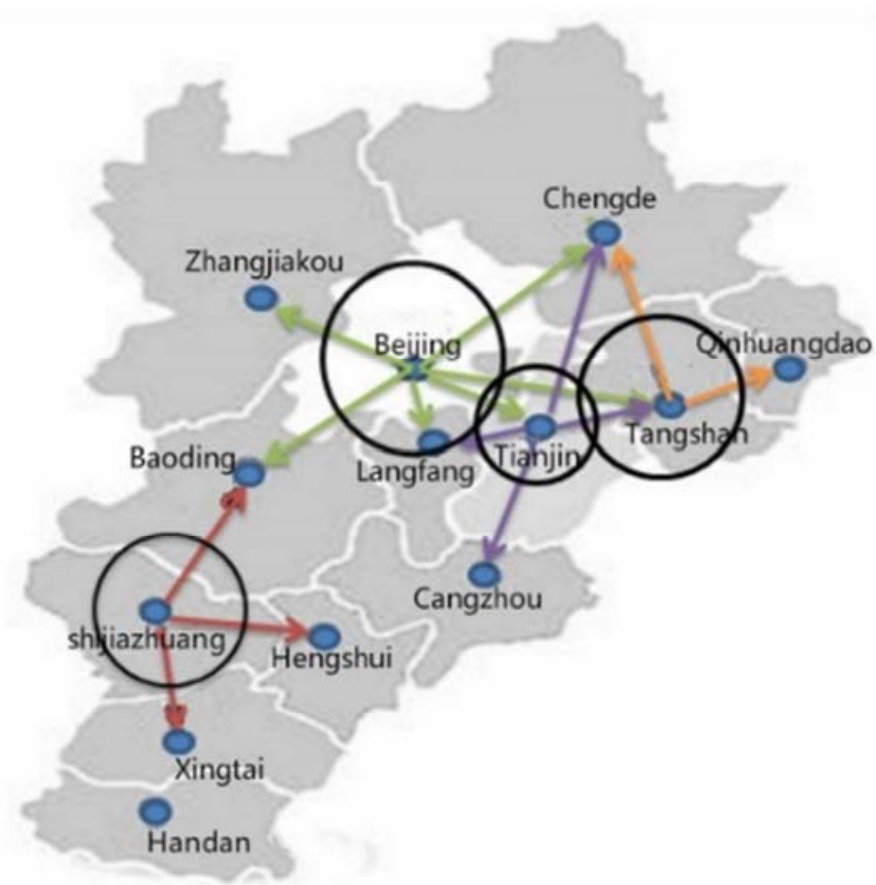

Figure 2. Radiation radius.

\section{Discussion}

Through evaluation on Logistics Competitiveness of Beijing - Tianjin - Hebei Regional Cities and the analysis of the logistics influence of the important cities, it can be seen that the Beijing-Tianjin-Hebei region still needs to make more efforts in the process of logistics development.

\subsection{Narrowing the Logistics Competitiveness Gap of the Node Cities}

Beijing's traffic congestion, resource shortage and other prominent urban problems have not been resolved yet. In Tianjin and Hebei, Transportation needs to be built, resources need to be developed. The function of logistics distribution of Beijing can be scattered to Tianjin and Hebei [5]. To improve 
the logistics competitiveness of the entire Beijing-Tianjin-Hebei region, it is imperative to take advantage of the logistics resources of each city of Beijing-Tianjin-Hebei and narrow the logistics competitiveness gap of key cities.

\subsection{Efforts to Improve the Logistics Competitiveness of Cities in Hebei Province}

From the factor 1 point of view, Shijiazhuang and Tangshan performed poorly on this factor, which shows that the weak competitiveness of two cities is caused by low overall level of regional economic development and poor Regional logistics environment. In order to improve the logistics competitiveness of Shijiazhuang and Tangshan, the government can improve the logistics infrastructure and build a good logistics environment [6].

Table 5. The rank of factor 1 for each city.

\begin{tabular}{lll}
\hline city & Factor 1 & rank \\
\hline Beijing & 3.185 & 1 \\
Tianjin & 0.524 & 2 \\
Shijiazhuang & 0.046 & 3 \\
Chengde & -0.461 & 12 \\
Zhangjiakou & -0.583 & 13 \\
Qinhuangdao & -0.399 & 10 \\
Tangshan & -0.392 & 7 \\
Langfang & -0.346 & 6 \\
Baoding & -0.036 & 4 \\
Cangzhou & -0.392 & 8 \\
Hengshui & -0.411 & 11 \\
Xingtai & -0.338 & 5 \\
Handan & -0.395 & 9 \\
\hline
\end{tabular}

\subsection{Break the Traffic Obstruction, Strengthen the City Logistics Cooperation}

The development of the logistics industry depends heavily on transportation facilities [6]. Taking Beijing as the center to the regional inland network of Beijing, Tianjin, a radial extension to the surrounding, the network structure makes many unrelated freight, passenger transport had to go through Beijing [7]. This kind of network makes great traffic pressure and higher logistics cost, and the logistics economy of Tianjin, Shijiazhuang, Tangshan and other cities is blocked by the Interregional traffic routes [8] [10]. Speeding up the construction of intercity railways, highways and other transportation facilities between the important cities and the other is urgent for the development of Beijing - Tianjin - Hebei.

\section{Conclusion}

The logistics influence of urban is the result of interaction between city's different logistics scale [11]. In this paper, the urban logistics influence of the Beijing-Tianjin-Hebei region is evaluated and measured by factor analysis and theory of break point: logistics influence of Beijing, Tianjin, Shijiazhuang, and Tangshan is greater than the other cities of the Beijing-Tianjin-Hebei region, but logistics influence of Shijiazhuang and Tangshan behind with Beijing and Tianjin.
What's more, the linkage effect of these four node cities is so weak that limited to the influence of the central city, the logistics development of Beijing-Tianjin-Hebei region has not formed the urban system of scale [12].

If central city expand the scale, function and regional influence of logistics healthily and quickly, at the same time the central cities strengthen logistics function integration and spatial relationship [9]. The logistics competitiveness of backward cities is likely to mature quickly.

\section{References}

[1] Tae Won Chung. A Study on Logistics Cluster Competitiveness among Asia Main Countries using the Porter's Diamond Model [J]. The Asian Journal of Shipping and Logistics. 2016, 32(4).

[2] Shuang Wang. Study of Core Competence of Logistics Cluster: The Integration and the Extension of Value Chain [J]. American Journal of Industrial and Business Management, 2015, 05(01).

[3] Yu Lan Qi, Shuang Liu. Integrated Model of Cluster Supply Chain and Logistics Park [J]. Applied Mechanics and Materials, 2015, 3675(697).

[4] Yan Weiyang, Qin Yaochen, Guo Yaochen. Verification, extension and application of the theory of urban fracture point [J]. Human geography, 2004, 19(2): 12-16.

[5] Chen Xiaochun, Research on the Status of Beijing-Tianjin-Hebei Logistics Operating, American Journal of Theoretical and Applied Statistics. Vol. 5, No. 5, 2016, pp. 297-304. Doi 10.11648/j.ajtas.20160505.18.

[6] Haughton G. Developing sustainable urban development model [J]. cities, 1997, 14(4): 189-195.

[7] CALLENT N. The rural-urban fringe: A new priority for planning policy? [J]. Planning Practice \& Research, 2006, 21(3): 383-393.

[8] ISHIKAWA T. TADA M. Some economic extensions of central-place theory involving profit maximization [J]. Urban Studies, 2000, 37(3): 481-495.

[9] OPENSHAW S. VENERIS Y. Numerical experiments with central place theory and spatial interaction modelling $[\mathrm{J}]$. Environment \& Planning, 2003. 35 (8): 1389-1403.

[10] Eiich, $\mathrm{T} \cdot$ Michihiko, N, Tadashi, Y, Toru, Ioptimal size and Location Planning of Public Logistics Terminal Transportion Research Part, 1999 (35): 207-222.

[11] Wei Yehua, Fan C Cindy. Regional Inequality in China: A Case Study of Jiangsu Province [J]. Professional Geography, 2000(3): 455 - 469 .

[12] Fan C Cindy. Development From Above. Below and Outside: Spatial Impacts of China's Economic Reforms in Jiangsu and Guangdong Province $[\mathrm{J}]$ Chinese Environment and Development, 1995(6): 85-116.

[13] Zhang Xiaoqian, Zhang Quanjing. Research on radiation ability of major cities in Shandong peninsula urban agglomeration [J]. Regional research and development, 2012, 31 (6): 66-69. 